UDK: $341.1 / .8$

Originalan naučni rad

Biblid: 1451-3188, 19 (2020)

Primljen 31.08.2020.

God XIX, br. 73-74, str. 5-16

Odobren 27.09.2020.

DOI: https://doi.org/10.18485/iipe_ez.2020.19.73_74.1

\title{
ODRŽIVOST KONCEPTA REGIONALNIH KOGENTNIH NORMI - OPŠTI SISTEM PROTIV EVROPSKOG SISTEMA
}

\begin{abstract}
Bojan MILISAVLJEVIĆ*
Apstrakt: U ovom radu predstavljena je analiza jednog novog i osetljivog pitanja od interesa za čitavu međunarodnu zajednicu - pitanje regionalnih kogentnih normi. Polazi se od aktuelnog rada Komisije za međunarodno pravo Ujedinjenih nacija i prate diskusije i komentari kako država tako i vodećih autora po ovom pitanju. Autor zauzima jasan stav da bi trebalo prihvatiti regionalne kogentne norme, s obzirom na to da one već kao takve postoje na području Evrope i to u sistemu Saveta Evrope i Evropskog suda za ljudska prava, ali i u sistemu Evropske unije. Ukazano je da regionalne kogentne norme postepeno bivaju prihvaćene i na drugim područjima, recimo na tlu Amerike, pa je to samo jedan od razloga za njihovo priznanje. Nažalost, članovi Komisije za međunarodno pravo još uvek nisu zauzeli stav o priznanju ovih normi, iako postoje značajni autori koji podržavaju njihovo prihvatanje. U radu je jasno pokazano da iako se često pitanje regionalnih kogentnih normi dovodi u vezu sa fragmentacijom međunarodnog prava, ovo predstavlja pozitivan aspekt. Naime, prihvatanje regionalnih kogentnih normi predstavljalo bi unapređenje čitavog međunarodnog prava, ali nikako po cenu postojanja opštih kogentnih normi. Autor insistira na tome da je područje Evrope bilo tlo gde se rodilo međunarodno pravo i gde je stepen integracije država na najvišem nivou, pa bi se preko regionalnih kogentnih normi unapredilo čitavo međunarodno pravo, kao i ljudska prava uopšte.

Ključne reči: regionalne kogentne norme, Savet Evrope, Evropska unija, Komisija za međunarodno pravo.
\end{abstract}

\footnotetext{
* Redovni profesor Pravnog fakulteta Univerziteta u Beogradu, E-mail: bojan@ius.bg.ac.rs.

Rad je nastao kao rezultat istraživanja u okviru strateškog projekta Pravnog fakulteta Univerziteta u Beogradu pod nazivom „Identitetski preobražaj Srbije“, za potprojekat „Pravo država i naroda na poštovanje nacionalnog identiteta“.
} 


\section{1) UVODNA IZLAGANJA}

Koncept kogentnih normi dobro je poznat u međunarodnoj teoriji, ali i praksi. ${ }^{1}$ Formalno su kogentne norme etablirane Konvencijom o ugovornom pravu iz 1969. godine, a značajno je njihova egzistencija podržana kroz praksu Međunarodnog suda pravde. Koncept peremptornih normi opšteg međunarodnog prava priznat je u međunarodnoj praksi, kao i u jurisprudenciji međunarodnih i nacionalnih sudova i tribunala, a tako i u doktrini. ${ }^{2}$ Smatra se da su ove norme neophodne i da veoma doprinose konstitucionalizaciji međunarodnog prava. ${ }^{3}$

Iako je koncept kogentnih normi kreiran pomenutom konvencijom opravdano je sledeće viđenje: Štaviše, do sada nije bilo prigovora da ideja jus cogens ima ili može imati uticaja na određene oblasti međunarodnog prava koje su izvan ugovornog prava. ${ }^{4}$ Dakle, nema sumnje da je zbog svog značaja pitanje kogentnih normi u grupi fundamentalnih pitanja od izuzetne važnosti za opšte međunarodno pravo. Iako postoje neki autori koji negiraju veliki značaj ovih normi, čak i oni smatraju da su još uvek prilično relevantne u međunarodnom pravu. Tako ih nazivaju praznom kutijom, koja još uvek ima izvesni značaj..$^{5}$

Vremenom dolazi do značajnih pitanja u vezi ovih normi koja imaju za posledicu rad Komisije za međunarodno pravo na njihovom pravnom regulisanju. ${ }^{6}$ Tako je specijalni izvestilac na jedan jezgrovit način izvukao osnovne osobine kogentnih normi: prvo - to su norme od kojih nije dopušteno nikakvo odstupanje, drugo - to su norme opšteg međunarodnog prava, treće - norme su prihvaćene i priznate od strane međunarodne zajednice kao celine, pa zbog toga nije dopušteno nikakvo odstupanje, četvrto - peremptorne norme su univerzalno primenjive, peto -ove norme su superiorne u odnosu na druge norme međunarodnog prava, i konačno kogentne norme služe da zaštite osnovne vrednosti međunarodne zajednice. ${ }^{7}$

\footnotetext{
${ }^{2}$ Ove norme po prvi put su pomenute u odluci Stalnog međunarodnog suda pravde još 1934. godine kada je sudija u izdvojenom mišljenju smatrao da su obaveze koje proizlaze iz Pakta društva naroda iznad svih drugih obaveza. Permanent Court of International Justice, The Oscar Chinn Case (Britain v. Belgium), Separate Opinion (Judge Schücking), 12 December 1934, at para. 341.

${ }^{3}$ IACtHR, Caesar Case, 2005, Separate Opinion Judge Cancado, para. 92.

${ }^{4}$ Cezary Mik, "Jus cogens in contemporary international law", Polish Yearbook of International Law, vol. 33, 2013, p. 92.

${ }^{5}$ Antonio Cassese, "For an Enhanced Role of Jus cogens", in A. Cassese (ed.), Realizing Utopia: the Future of International Law, 2012, p. 163.

${ }^{6}$ Abi-Saab, "The Third World and the Future of the International Legal Order", 29 Revue Egyptienne de Droit International,1973, p. 53.

${ }^{7}$ International Law Commission (ILC), Report on the Work of Its Sixty-Seventh Session (4 May-5 June and 6 July-7 August 2015), UN Doc. A/71/10, 14 August 2015, para. 286.
} 
Ovakav stav je u potpunosti zasnovan na definiciji ovih normi iz Konvencije o ugovornom pravu: Ugovori koji su suprotni imperativnoj normi opšteg međunarodnog prava (ius cogens) - Ništav je svaki ugovor koji je u trenutku sklapanja suprotan imperativnoj normi opšteg međunarodnog prava. U svrhu ove Konvencije, imperativna norma opšteg međunarodnog prava je norma koju je prihvatila i priznala čitava međunarodna zajednica država kao normu od koje nije dopušteno nikakvo odstupanje i koja se može izmeniti samo novom normom opšteg međunarodnog prava iste prirode. ${ }^{8}$

Istovremeno se otvara prostor za delovanje u smislu progresivnog razvoja vezanog za kogentne norme. Relevantni autori postavljali su puno pitanja u vezi ovih normi: 1. kako odrediti nastanak i kapacitet kogentnih normi, 2. kako objasniti uticaj ovih normi na direktan ili indirektan način na unutrašnji pravni poredak i probijanje štita državnog suvereniteta, 3. koji su sve međunarodni sudski metodi dostupni u slučaju spora o postojanju i domašaju kogentnih normi. ${ }^{9}$ Ideja je da se u ovom radu osvetle neka druga pitanja koja su značajna u ovom trenutku, a neke odgovore na prethodno pokrenuta pitanja već je dala Komisija za međunarodno pravo u dosadašnjem radu na ovim normama. Pre svega, rad će se baviti mogućnošću postojanja regionalnih kogentnih normi naspram opštih kogentnih normi kroz prizmu prava Saveta Evrope i Evropske unije. Iako na univerzalnom planu i u radu Komisije za međunarodno pravo još uvek nema dovoljno podrške konceptu regionalnih normi, ovaj rad je jedan mali doprinos njihovom utemeljenju i objašnjenju takvih težnji. Naročita pažnja posvećena je ukazivanju da prihvatanje regionalnih kogentnih normi ne mora biti štetno po opšte međunarodno pravo i utemeljene univerzalne kogentne norme, a negativni predznak koji ističu neki autori tiče se pitanja fragmentacije međunarodnog prava. ${ }^{10}$

\section{2) REGIONALNE KOGENTNE NORME - ZA I PROTIV}

Pored brojnih pitanja koja su u vezi ovih normi pokrenuta, nalazi se i sledeće pitanje: Može li postojati regionalna kogentna norma? Da li se ona uklapa u postojeću regulativu kogentnih normi? Ako se pođe od definicije kogentnih normi i člana 53 svojstvo takve norme može imati samo norma opšteg međunarodnog prava. Dakle, kada se radi o regionalnim kogentnim normama onda se nesporno odstupa od toga i daje mogućnost da neka norma koja nije deo opšteg međunarodnog prava postane kogentna ili bolje reći koja na univerzalnom planu nema karakter kogentne norme. Kao jedan od primera regionalnog ius cogensa

\footnotetext{
${ }^{8}$ ILC, First Report on jus cogens by Dire Tladi, Special Rapporteur, UN Doc. A/CN.4.693, 8 March 2016, paras 61-63.

${ }^{9}$ Član 5, Konvencije o ugovornom pravu.

${ }^{10}$ Ibidem, 163.
} 
može se navesti pravo na život koje egzistira kao opšteprihvaćeno u okviru Saveta Evrope. Ovo osnovno ljudsko pravo je jedino apsolutno zaštićeno na tlu Evrope i takva činjenica je vredna poštovanja. Nažalost, na univerzalnom planu se to ne može reći. Postavlja se opravdano pitanje: Da li takva pravna norma šteti opštem međunarodnom pravu i konceptu kogentnih normi? Meni se čini da je odgovor negativan. Podizanjem nivoa zaštite ljudskih prava u regionu Evrope samo se doprinosi unapređenju zaštite ljudskih prava i daje dobar primer drugim regionima.

Regionalne kogentne norme se ne uklapaju ni u karakteristike koje su navedene u prvom izveštaju specijalnog izvestioca i to na tačku dva - kada kaže da su to norme koje su prihvaćene od strane cele međunarodne zajednice, kao i tri - kada kaže da se primenjuju na opštem planu. Ipak, postavlja se pitanje može li se, pravno gledano, ipak prihvatiti koncept regionalnih kogentnih normi ili je to nemoguće u ovom trenutku? Mogu li se izvršiti potrebne modifikacije koje bi ipak otvorile mogućnost prihvatanja ovih normi? Čini se da bi se moglo shvatiti da ove norme ne moraju nužno da ugrožavaju opšti koncept kogentnih normi, već ga mogu upotpuniti i obogatiti. U ovom radu će biti pokušaja da se to dokaže.

Ukoliko se prihvati teza da su regionalne kogentne norme prihvatljive i moguće, onda se otvaraju na taj način druga pitanja. Kakav je njihov odnos sa opštim peremptornim normama? Bilo bi racionalno očekivati da regionalne norme moraju biti podređene opštim normama. Ali tu nije kraj pitanjima. Navikli smo da kogentne norme imaju apsolutni primat u odnosu na sve druge norme međunarodnog prava, ali uvođenjem regionalnih kogentnih normi stvaraju se iste takve norme na regionalnom planu. To sve može uticati na obaveze država, primenu pravila u praksi. Pored toga, prihvatanje regionalnih kogentnih normi znači i potvrdu fragmentacije međunarodnog prava. Dalje, nije jasno kakav je odnos recimo kogentnih normi i opštih pravila međunarodnog prava sa kojim su regionalne norme u sukobu ili barem u nesaglasju? Deluje racionalno da i pored imperativne snage regionalnih normi države i dalje moraju da poštuju opšta pravila međunarodnog prava.

Pošto smo videli da su regionalne kogentne norme drugačije od univerzalnih po tome što ih nisu prihvatile države članice međunarodne zajednice kao celine, neophodno je utvrditi pojam regiona i opšteprihvaćenost. Ranije je navođeno područje Evrope kao mesto gde se pojavljuje pravo na život kao regionalna kogentna norma. Deluje da bi definicija kogentne norme mogla biti sledeća: da je to apsolutno obavezujuća norma regionalnog međunarodnog prava koja je prihvaćena od strane svih drugih članica tog regiona i koja bi mogla biti menjana samo takvom istom normom. Ova definicija je rađena po ugledu na definiciju opšte kogentne norme. Pored ove definicije neophodno je da se uredi njen odnos sa univerzalnom kogentnom normom. Činjenica da je Komisija za međunarodno pravo prihvatila da analizira regionalne kogentne norme u sklopu rada na univezalnim, znači da je svesna da postoje potrebe o njima. Ipak, nema sumnje da je uvođenjem 
regionalnih kogentnih normi učinjen korak u pravcu progresivnog razvoja, ${ }^{11}$ jer one nisu prihvaćene u praksi i nemaju još uvek svoju formalnopravnu fizionomiju. Sa druge strane, mora se imati u vidu i nesporni razvoj međunarodnog prava u međuvremenu. Naime, rad na Konvenciji o ugovornom pravu trajao je jako dugo i započeo je ubrzo po formiranju Komisije za međunarodno pravo, tj. pedesetih godina prošlog veka. Sada, nakon sedamdeset godina prirodno je da dolazi do unapređenja pravnih pravila, pa i samih kogentnih normi. Naročito se mora imati $\mathrm{u}$ vidu da ukoliko se prihvate regionalne kogentne norme to nikako ne treba shvatiti u smislu sukoba sa univerzalnim kogentnim normama, već upravo kao jednu pravno logičku simbiozu. Dakle, regionalne kogentne norme nikako ne smeju da se suprotstavljaju opštim kogentnim normama.

Jedan od prvih problema na koje je ukazivano u radu Komisije prilikom navođenja regionalnih kogentnih normi jeste njihovo odstupanje od monolitne strukture opštih peremptornih normi. Tako se primećuje: Iako postoje neki autori koji smatraju da je regionalni ius cogens moguć, osnova za to ostaje pomalo nejasna. Budući da ako postoji regionalni ius cogens to bi bio izuzetak od ovog opšteg principa univerzalne primene normi jus cogens. ${ }^{12}$ Kada je reč o stavu država povodom regionalnih kogentnih normi deluje da one imaju prilično otpora. Tako je predstavnik Malezije istakao da smatra da uvođenje ovih normi ne bi bilo u skladu sa univerzalnim kogentnim normama, te da bi prouzrokovalo konfuziju, pa prema tome ne bi trebalo da budu prihvaćene. ${ }^{13}$ Nešto slično je stav i Velike Britanije kada je njen predstavnik zaključio da bi se time uzdrmao režim univerzalnih kogentnih normi. ${ }^{14} \mathrm{U}$ doktrini, međutim, postoje pristalice regionalnih kogentnih normi pa se navodi autor Robert Kolb, ${ }^{15}$ ali i neki drugi autori. ${ }^{16}$ Oni prihvataju slobodniju i široku formu kogentnih normi pa smatraju da se tu mogu ubrojati i pravila sudskog postupka koja se ne mogu derogirati. Zbog toga je njima bliska i ideja regionalnog

${ }^{11}$ Za pojam fragmentacije pogledati: Martti Koskenniemi, "Fragmentation of International Law: Difficulties Arising from the Fragmentation and Expansion of International Law", Report of the Study Group of the International Law Commission, UN Doc. A/CN.4/L.682, 2006.

${ }^{11}$ Videti: Allan Pellet, “Comments in response to Christine Chinkin and in defense of jus cogens as the best bastion against the excesses of fragmentation", Finnish Yearbook of International Law, vol. 17, 2006.

${ }^{12}$ A/CN.4/693, para. 68.

${ }^{13}$ Malaysia (A/C.6/73/SR.27).

${ }^{14}$ United Kingdom (statement of 30 October 2018; see also A/C.6/73/SR.27).

${ }^{15}$ Robert Kolb, Peremptory International Law (Jus Cogens): A General Inventory, Oxford, Hart, 2015.

${ }^{16}$ Ulf Linderfalk, "Understanding the jus cogens debate: the pervasive influence of legal positivism and legal idealism", Netherlands Yearbook of International Law, vol. 46 (2015). 
kogentnog pravila. Deluje da ovi autori ulaze u zamku tumačenja pravnih normi. Čini se da oni epitet kogentnih normi daju svakoj pravnoj normi koja ima sankciju u međunarodnom pravu. Jasno je da se idealna pravna norma sastoji od dispozicije i sankcije, pa ih zato ne treba sve smatrati kogentnim normama. U suprotnom bi se ušlo u jedno bezobalno tumačenje svih pravnih pravila međunarodnog prava kao kogentnih pravila.

Međutim, povodom regionalnih kogentnih normi stvari nisu tako crno bele. Pored negativnih stavova postoje i stavovi koji idu u prilog regionalnih kogentnih normi, a koji dolaze od veoma respektabilnih autora. Tako sudija Međunarodnog suda pravde Gaja zaključuje sledeće: Konvencija (misli se na Konvenciju o ugovornom pravu) ukazuje da se obavezne norme nužno odnose na „opšte međunarodno pravo” i da se primenjuju na „međunarodnu zajednicu država u celini". Nikada nije naveden ubedljiv razlog koji bi isključio mogućnost postojanja univerzalnih ili „regionalnih“ peremptornih normi. Vrednosti koje prevladavaju u regionalnim grupama nisu nužno u sukobu sa vrednostima koje deluju u širem okviru. Mogu postojati norme koje poprimaju peremptorni karakter samo u regionalnom kontekstu. ${ }^{17}$ Smatram da je ovaj put dobar jer ističe upravo onu karakteristiku po kojoj su kogentne norme specifične, a to su opšteprihvaćene vrednosti. Ne vidim zbog čega, pored nespornih univerzalnih vrednosti, države članice jednog regiona ne bi mogle da imaju i sopstvene vrednosti koje ni u čemu nisu u sukobu sa univerzalno prihvaćenim vrednostima. Problem je što se zbog straha da se ničim ne ugrozi koncept kogentnih normi na univerzalnom planu stvari posmatraju iz negativnog ugla, pa se polazi od nužne kolizije takvih pravila. Smatram da je moguće prihvatiti regionalni koncept kogentnih normi, ali uz uslov da nema suprotstavljanja univerzalnim normama. Povodom koncepta kogentnih normi akcenat je pored njihove imperativnosti i u vrednosnom karakteru. Tako se povodom kogentnih normi ističe: to su ona pravila koja su proistekla od principa koje je pravna savest čovečanstva ustanovila i koje smatra apsolutno neophodnim za suživot u međunarodnoj zajednici u datoj fazi svog istorijskog razvoja. ${ }^{18}$ Ukoliko je na određenom regionu došlo do uspostavljanja takve svesti povodom nekog pravila i ako ono ne protivureči opštim imperativnim normama, onda je takva situacija i legalna i legitimna u potpunosti.

Na sličan način rezonuje i Alan Pele koji otvara mogućnost postojanja kogentnih normi na regionalnom planu i tu upravo navodi sistem zaštite ljudskih prava u

\footnotetext{
${ }^{17}$ Giorgio Gaja, "Jus cogens beyond the Vienna Convention", Collected Courses of the Hague Academy of International Law, 1981-III, vol. 172, p. 284.

${ }^{18}$ Videti: UN Committee of the Whole, Official Records of the United Nations Conference on the Law of Treaties, First Session, UN Doc. A/CONF.39/C.1/SR.52 (1968), p. 294, para. 7, available at: http://untreaty.un.org/cod/diplomaticconferences/lawoftreaties-1969/docs/ english/1stsess/a_conf_39_c1_sr52.pdf.
} 
sistemu Saveta Evrope. ${ }^{19}$ Postoje donekle opravdani prigovori da bi se prihvatanjem regionalnog kogentnog sistema usložnio odnos država i da bi se na taj način uvela pravna nesigurnost u ionako decentralizovanu međunarodnu zajednicu. To je samo donekle tačno. Ne vidi se kako je sistem koji funkcioniše u okviru Saveta Evrope i koji efikasno štiti ljudska prava ugrozio opšti sistem normi međunarodnog prava. Ako se na nekom regionalnom sistemu podiže nivo zaštite nekih prava, to ne može da ugrozi univerzalni sistem zaštite prava koji je na nižem nivou. Iz ovoga proizlazi da sistem regionalnih kogentnih normi ne može da ugrozi, već može da učini efikasnijim i boljim primenu pravila međunarodnog prava. Pogotovo ukoliko se ima $\mathrm{u}$ vidu da postoje regioni koji imaju veliki stepen bliskosti usled vekovnih veza koje su postojale u pogledu kulture, religije, ekonomije, a na osnovu kojih je moguće zamisliti viši stepen integracije nego one koja objektivno postoji na univerzalnom planu. Takve okolnosti idu u prilog regionalnim kogentnim sistemima, a nikako ne ugrožavaju univerzalni sistem ovih normi.

Ako su uzme u obzir region Evrope onda se ne sme zaboraviti da je to područje upravo i bilo kolevka čitavog međunarodnog prava, što potvrđuje činjenicu da na tom području jeste realno očekivati najviši stepen integracije država. Ovo za potvrdu ima i najčvršći savez država u obliku Evropske unije. Ukoliko je čitavo međunarodno pravo nastalo na ovom području zašto ne bi moglo da dođe do nastanka regionalnih režima kogentnih normi. Veoma respektabilni autori realno posmatraju stvari kada zaključuju: postoji evropski sistem kogentnih ljudskih prava koji je svakako složeniji i zahtevniji od veoma labave mreže ljudskih prava na svetskom nivou. ${ }^{20}$ Ako se slažemo da opšti sistem kogentnih normi teži humanizaciji pravila onda je trend poboljšanja zaštite opštih ljudskih prava poželjan i koristan.

U praksi bi sigurno nastajali problemi ukoliko se prihvati režim regionalnih normi, tako da bi države članice tog regiona u istoj stvari imale obavezu da striktno poštuju takve norme u međusobnim odnosima, a da to ne moraju da čine kada istupaju prema drugim državama izvan tog regiona. Kako bi se u tom slučaju branila njihova apsolutna obaveznost i efekat apsolutne ništavosti u slučaju sukoba sa njima? Pitanje regionalnih kogentnih normi nesporno je povezano sa fragmentacijom međunarodnog prava. ${ }^{21}$ Pored teorije i praksa je išla u negativnom smeru kada je u slučajevima pred Evropskim sudom pravde došlo do tumačenja opštih imperativnih pravila i odluka Saveta bezbednosti Ujedinjenih nacija. Tako je

\footnotetext{
${ }^{19}$ Allan Pellet, "Comments in response to Christine Chinkin and in defense of jus cogens as the best bastion against the excesses of fragmentation", Finnish Yearbook of International Law, vol. 17, 2006, p. 89.

${ }^{20}$ Ibidem

${ }^{21}$ Videti: Martti Koskenniemi, Fragmentation of International Law: Difficulties Arising from the Fragmentation and Expansion of International Law, Report of the Study Group of the International Law Commission, UN Doc. A/CN.4/L.682, 2006.
} 
u slučajevima Kadi ${ }^{22}$ i Jusuf ${ }^{23}$ Evropski sud pravde zaključio da su osnovna ljudska prava kogentne norme i samim tim iznad odluka Saveta bezbednosti. U suštini, $s$ obzirom na to da se zna da je na tlu Evrope obezbeđen najviši stepen zaštite ljudskih prava, moglo bi se zaključiti da se radi o regionalnom kogentnom pravilu koje je stavljeno nasuprot prava Ujedinjenih nacija. Ovakav pristup je pogrešan i naišao je na brojne kritike. Nema sumnje da regionalne kogentne norme nikako ne mogu biti više pravne snage od odluka Saveta bezbednosti, iako pojedini autori tvrde da odluke Saveta bezbednosti može da kontroliše Evropski sud pravde. ${ }^{24} \mathrm{Za}$ ovakve stavove se ne može pronaći nikakvo ozbiljno pravno utemeljenje. Zbog posebnih odredbi o važenju pravila o ljudskim pravima, države članice Saveta Evrope mogu biti odgovorne za povrede Konvencije o ljudskim pravima i osnovnim slobodama i prema državljanima drugih država. Ovde se situacija komplikuje jer su te iste države Evrope ujedno i obavezane pravom Ujedinjenih nacija. S jedne strane, obaveze prema Povelji su iznad drugih obaveza država, a i pravo Ujedinjenih nacija je starije pravo i u vremenskom smislu pa bi važila latinska maksima prior in tempore potior in iure. Pored poštovanja pravnih pravila kao takvih postavlja se pitanje i poštovanja prava međunarodne organizacije, pa bi tu svakako imale prednost Ujedinjene nacije i zbog odredaba iz glave osam Povelje koja uređuje odnose te organizacije sa regionalnim organizacijama. I neke druge regionalne organizacije iznosile su svoje viđenje u vezi regionalnih kogentnih normi. Tako je Međuamerička komisija za ljudska prava još 1987. godine zaključila da je zabrana državne egzekucije nad licima mlađim od 18 godina kogentna norma država članica i da postoji opšta saglasnost u vezi toga. ${ }^{25}$ Isti stav potvrdila je i 2002. godine konstatujući da se radi o nespornoj i opšteprihvaćenoj kogentnoj normi tog regiona. ${ }^{26}$ Ako se uzme u obzir da se na tlu Evrope i Amerike pojavljuju ovakve tendencije, onda se ne može tvrditi da nema prakse država ili međunarodnih tela u prilog konceptu regionalnog kogentnog prava.

Postoje autori koji posmatraju pojam regionalnih kogentnih normi kroz pravni poredak, pa nasuprot opštem pravnom poretku postavljaju regionalni i tumače njihov međusobni odnos. Prethodno pitanje jeste određivanje hijerarhije normi na univerzalnom planu. Tako se na čelu svakako nalaze kogentne norme, kao i načela

\footnotetext{
${ }^{22}$ Kadi v. Council and Commission (2005) ECR II-3649.

${ }^{23}$ Case T-306/01, Yusuf and AI Barakaat InternationalFoundation v. Council and Commission (2005) ECR II-3533, para. 337.

${ }^{24}$ Hinojosa Martinez, "Bad Law for Good Reasons: The Contradictions of the Kadi Judgement", 5 International Organizations Law Review, 2008, pp. 352-353.

${ }^{25}$ Roach and Pinkerton v. United States, Case No. 9647, resolution No. 3/87, Inter-American Commission on Human Rights, 22 September 1987, para. 56.

${ }^{26}$ Michael Domingues v. United States, Case No. 12.285, Merits, Inter-American Commission on Human Rights, 22 October 2002, para. 85.
} 
međunarodnog prava, zatim su to sve norme koje imaju erga omnes dejstvo, poput opštih običajnih pravila i koja obavezuju države čitave međunarodne zajednice. Dakle, sve kogentne norme imaju erga omnes dejstvo, ali sve norme koje imaju erga omnes dejstvo nisu ujedno i kogentne norme. ${ }^{27} \mathrm{Na}$ istom nivou obaveznosti svakako su opšta pravna načela, kao i obavezujuće odluke Saveta bezbednosti Ujedinjenih nacija. Ova organizacija je učinila do sada jako puno na normativnom ustrojstvu međunarodnog prava pa je ispravno reći sledeće: bilo bi fer zaključiti da normativni okvir Povelje Ujedinjenih nacija jeste od presudne važnosti za vertikalizaciju u odnosima država članica inter $s .^{28}$ Ovaj sistem je omogućio da se vremenom uspostave i kristalizuju opšte vrednosti koje su u osnovi svake kogentne norme. Sigurno je da je i pre Povelje postojao veliki korpus običajnih pravila koja su značajno pomogla da se izgradnjom institucije Ujedinjenih nacija uobliči univerzalni pravni poredak. Da bi se ispravno tumačio odnos kogentnih normi i prava Ujedinjenih nacija potrebno je poći od sledećeg: ukoliko je ugovorno pravo potčinjeno kogentnim normama, to važi takođe i za pravo koje proizlazi ugovornog prava, bez obzira na član 103 Povelje, zato sledi implicitno i nužno da su svi organi Ujedinjenih nacija dužni da poštuju kogentne norme. ${ }^{29}$ Ovakav stav je logički potpuno ispravan, ali mora se postaviti pitanje da li je Povelja Ujedinjenih nacija običan ugovor ili je ipak to ugovor višeg tipa zaključen iz interesa koji su vrhovne vrednosti same međunarodne zajednice i civilizacije uopšte. Sa druge strane, i sam tekst Povelje sadrži u sebi kogentne norme kao što je u prethodnom delu teksta navedeno. Član 103 uveden je da bi se očuvalo opšte međunarodno pravo kao i da bi odnos Povelje kao međunarodnog ugovora bio superioran u odnosu na druge ugovorne režime, ali i u odnosu na druge izvore obaveza za države prema nekim drugim aktima. Pored ovoga nema sumnje da su organi Ujedinjenih nacija u obavezi da poštuju pravila međunarodnog prava $^{30}$ - pa time naravno i kogentne norme već i same odluke organa ove organizacije koje su donete u skladu sa procedurom i pravom Ujedinjenih nacija, ${ }^{31}$ imaju obavezujuću snagu i prednost u hijerarhiji u odnosu na druge obaveze država iz recimo regionalnih režima. Ovo tim pre jer su sve države, ma kom regionu pripadale, ujedno i članice Ujedinjenih nacija, pa bi tako prekršile i svoje obaveze koje su same prihvatile stupajući u univerzalnu

\footnotetext{
${ }^{27}$ Erika DeWet, “The International Constitutional Order", ICLQ, vol 55, 2006, pp 51-76.

${ }^{28}$ Erika de Wet, "The emergence of international and regional value systems as a manifestation of the emerging international constitutional order", Leiden Journal of International Law, vol. 19, 2006, p. 616.

${ }^{29}$ Allan Pellet, "Comments in response to Christine Chinkin and in defense of jus cogens as the best bastion against the excesses of fragmentation", op. cit., p. 86.

${ }^{30}$ Ovo je detaljnije regulisano članom 25 Povelje u odnosu na Savet bezbednosti.

${ }^{31}$ Karl Zemanek, "The Legal Foundations of the International System”, RCADI, 1997, vol. 266, p. 231.
} 
organizaciju. Na osnovu navedenog može se zaključiti da nema potrebe stavljati u sukob kogentne norme i član 103 Povelje, niti celokupni sistem Ujedinjenih nacija, već upravo suprotno.

Sa druge strane, postojanje regionalnih režima u kojima se gaji velika objektivna kohezija u pogledu zajedničkih vrednosti, kao što je to slučaj sa Evropskom unijom, dovodi do pitanja kakav je njihov odnos sa pravilima opšteg međunarodnog prava. Deluje da je prenaglašeno govoriti o potencijalnoj dominaciji evropskog poretka nad univerzalnim, imajući u vidu da se ovi sistemi u velikoj meri poklapaju. To potvrđuje i praksa pred Evropskim sudom za ljudska prava. ${ }^{32}$ Deluje da nisu problem sama prava koja se pojavljuju u jednom i u drugom pravnom sistemu, ona se u velikoj meri poklapaju po svojoj sadržini. Deluje da je veći problem u pogledu zaštite prava jer se na univerzalnom planu ona štite na nešto fleksibilniji način, dok su ona u sistemu Saveta Evrope zaštićena mnogo efkasnije. ${ }^{34}$

\section{3) ZAKLJUČNA RAZMATRANJA}

Upravo zbog toga što postoje argumenti i za, ali i protiv uvođenja koncepta kogentnih normi u međunarodnom pravu, u radu komisije nije bio posebnih zaključaka, bar ne za sada. Zaključeno je sledeće: U svetlu gornje analize može se zaključiti da pojam regionalnih kogentnih normi ne nalazi podršku u praksi država. Iako je nacrt Komisije izričit u tom pogledu, specijalni izvestilac smatra da tako nešto nije potrebno još uvek uvrstiti u pravila već da bi o tome trebalo sačiniti odgovarajući komentar i objašnjenje. ${ }^{34}$ Meni deluje da se u ovom radu Komisije moglo otići i jedan važan korak dalje. Smatram da nije tačno da regionalne kogentne norme ne nalaze svoje mesto u praksi međunarodnih tela i država. U ovom radu su navedeni dokazi da se regionalne kogentne norme mogu prepoznati i pronaći u radu pre svega Evropskog suda za ljudska prava, ali i Inter-američke komisije za ljudska prava. Ovu ideju podržavaju i neki veoma respektabilni autori međunarodnog prava, pa deluje da se radi o svojevrsnom pravcu ka progresivnom razvoju pravila međunarodnog prava. Ne vidim zašto i same kogentne norme ne bi malo evoluirale pogotovo u pravcu koji je napredan. Ako znamo da se ljudska prava na međunarodnom planu štite do određene mere i na određeni, ne tako efikasan način, zašto ne bismo prihvatili da se na regionalnom planu dopusti viši standard

${ }^{32}$ Al Adsani v. United Kingdom, Judgment, 21 November 2001, para. 55, available at http:/cmiskp.echr. coe.int.

${ }^{33}$ Erika de Wet, "The emergence of international and regional value systems as a manifestation of the emerging international constitutional order", Leiden Journal of International Law, vol. 19, 2006, p. 631.

${ }^{34}$ Special Rapporteur Dire Tladi, "Fourth report on peremptory norms of general international law (jus cogens)" International Law Commission, Seventy-first session, para. 47. 
zaštite. Takvo postupanje ide u prilog efikasnijoj zaštiti ljudskih prava, a ideja o regionalnom kogentnom pravilu Evrope ni u čemu ne šteti opštem režimu kogentnih normi na univerzalnom planu.

Verovatno je određeni otpor prema regionalnim kogentnim normama nastupio zbog neprhvatanja fragmentacije i želje da se po svaku cenu očuva univerzalni pravni koncept. Takvi napori su opravdani, ali je bolje normativno urediti opšti odnos prema pravilima koja nastaju u praksi, nego ignorisati njihovo postojanje. Regionalni sistemi i režimi će se razvijati i usavršavati, i upravo zbog toga je poželjno da ukoliko već nije moguće istom dinamikom razvijati opšti sistem razvoja pravila i njihove zaštite, onda barem treba urediti njihovo postojanje i uklopiti ga normativno u opšti sistem pravnih pravila, u ovom slučaju u sistem kogentnih normi.

\section{LITERATURA}

Abi-Saab, "The Third World and the Future of the International Legal Order", 29 Revue Egyptienne de Droit International, 1973.

De Wet, Erika, "The emergence of international and regional value systems as a manifestation of the emerging international constitutional order", Leiden Journal of International Law, vol. 19, 2006.

De Wet, Erika, "The International Constitutional Order", ICLQ vol 55, January 2006.

Dire, Tladi, Special Rapporteur, "Fourth report on peremptory norms of general international law (jus cogens)", International Law Commission Seventy-first session.

Gaja, Giorgio, "Jus cogens beyond the Vienna Convention", Collected Courses of the Hague Academy of International Law, vol. 172, 1981.

ILC, First Report on jus cogens by Dire Tladi, Special Rapporteur, UN Doc. A/CN.4.693;

International Law Commission (ILC), Report on the Work of Its Sixty-Seventh Session (4 May-5 June and 6 July-7 August 2015), UN Doc. A/71/10, 14 August 2015.

Kolb, Robert, Peremptory International Law (Jus Cogens): A General Inventory, Oxford, Hart, 2015.

Koskenniemi, Martti, Fragmentation of International Law: Difficulties Arising from the Fragmentation and Expansion of International Law, Report of the Study Group of the International Law Commission, UN Doc. A/CN.4/L.682 (13 April 2006).

Linderfalk, Ulf, "Understanding the jus cogens debate: the pervasive influence of legal positivism and legal idealism", Netherlands Yearbook of International Law, vol. 46, 2015. 
Martinez, Hinojosa, "Bad Law for Good Reasons: The Contradictions of the Kadi Judgement", 5 International Organizations Law Review, 2008.

Mik, Cezary, "Jus cogens in contemporary international law", Polish Yearbook of International Law, vol. 33 (2013), Cassese, For an Enhanced Role of Jus cogen', in A. Cassese (ed.), Realizing Utopia: the Future of International Law, 2012.

Pellet, Allan, "Comments in response to Christine Chinkin and in defense of jus cogens as the best bastion against the excesses of fragmentation", Finnish Yearbook of International Law, vol. 17, 2006.

UN Committee of the Whole, Official Records of the United Nations Conference on the Law of Treaties, First Session, UN Doc. A/CONF.39/C.1/SR.52 (1968).

Zemanek, Karl, The Legal Foundations of the International System, RCADI 1997, vol. 266.

\section{SUSTAINABILITY OF THE CONCEPT OF REGIONAL COGENT NORMS - GENERAL SYSTEM AGAINST THE EUROPEAN SYSTEM}

Summary: This paper presents an analysis of a new and sensitive issue of interest to the entire international community - the issue of regional ius cogens norms. It starts from the current work of the United Nations Commission on International Law and follows discussions and comments from both states and leading authors on this issue. The author takes a clear position that regional ius cogens norms should be accepted, considering that they already exist as such in Europe within the system of the Council of Europe and the European Court of Human Rights, but also in the system of the European Union. It was pointed out that regional cogent norms are gradually being accepted in other areas, for example, on American soil, so that is only one of the reasons for their recognition. Unfortunately, members of the International Law Commission have still taken a stand on the recognition of these norms, although some significant authors support their acceptance. The paper clearly shows that although the issue of regional ius cogens norms is often associated with the fragmentation of international law, this is a positive aspect. Namely, the acceptance of regional ius cogens norms would represent the improvement of the entire international law, but not at the cost of the existence of general ius cogens norms. The author insists that the area of Europe was the ground where international law was born and where the degree of integration of states is at the highest level, so the entire international law, as well as human rights in general, would be improved through regional coherent norms.

Keywords: regional ius cogens norms, Council of Europe, European Union, Commission on International Law. 